\title{
РОССИЯ - ПРЕЗИДЕНТСКАЯ РЕСПУБЛИКА: КОНСТИТУЦИОННО-ПРАВОВОЕ ИССЛЕДОВАНИЕ
}

\section{RUSSIA - PRESIDENTIAL REPUBLIC: CONSTITUTIONAL AND LEGAL RESEARCH}

S.V. Navalny, K.I. Aleksandrova

Сегодня среди ученых-теоретиков государства и политологов остро стоит вопрос о форме правления, сбормировавшейся в России на основе принятия Конституции 1993 года и готовящихся в настоящее время новых поправок, в которых вновь будут затронуты данные аспекты. В настоящее время в науке конституционного права единая позиция относительно формы правления, сформировавшейся в РФ, отсутствует. Сложившаяся практика позволяет выделить следующие виды республики: парламентскую, президентскую, смешанную, суперпрезидентскую и множество других. При этом в рамках отдельного вида республики могут существовать подвиды (например, Россия сегодня, по мнению ряда авторов, представляет собой «президентскую республику с сильной исполнительной властью»). Имеют место и другие мнения. Так, ряд ученых-правоведов полагают, что по форме правления современная Россия, во-первых, смешанная республика (О.Е. Кутабин, В.И. Фадеев); во-вторьх, президентская (М.Н. Марченко, В.С. Нерсесянц, Л.А. Морозова, В.Е. Чиркин); в-третьих, суперпрезидентская. Авторы считают, что Россия по факту является президентской республикой. При этом под президентской республикой считается та форма правления, в которой основным действующим субъектом является глава государства. Исходя из этого, целесообразным является установление сущностных признаков указанных видов республики. Речь идет о формально-определенных признаках, наличии отдельных конституционно-правовых норм, учете политикоправовой действительности. Ответ скрыт в понятии формы правления и опосредованно через нее - в сущности власти, ее влиянии на отношения, формирующиеся в государстве. Для того чтобы понимать позиции, раскрывающие данный процесс, проведено теоретическое конституционно-правовое исследование. Рассматриваются позиции различных авторов на данный вопрос, обобщается исторический материал и обосновываются выводы. Следуя нормам конституциионного права, необходимо подчеркнуть, что по формальноправовым основаниям формой правления современной России является президентская республика, несмотря на то, что в ней присутствует ряд признаков, свойственньх суперпрезидентской республике. Вносимые в Конституцию изменения позволят окончательно определиться с этим вопросом. 
Ключевъе слова: республика, президентская республика, сравнительно-правовой анализ, форма правления, сменяемость власти, выборы.

Today among the scientists-theorists of the state and political scientists the question of the form of the government created in Russia on the basis of the adoption of the Constitution of 1993 and new amendments being prepared now in which these aspects will be studied again is particularly acute. Now in the science of constitutional law a uniform position concerning the form of the government created in the Russian Federation is missing. Established practices allow allocating the following views of the republic: parliamentary, presidential, mixed, superpresidential, and a great number of others. Thus within a separate view of the republic there can be subspecies (for example, Russia today, according to a number of authors, represents "presidential republic with strong executive power"). And there are other points of view. So, a number of scientists-jurists believe that the form of government of modern Russia, first, mixed republic (O.E. Kutafin, V.I. Fadeev); secondly, presidential (M.N. Marchenko, V.S. Nersesyants, L.A. Morozova, V.E. Chirkin); thirdly, superpresidential. It is considered by the authors that Russia is presidential republic. Thus under presidential republic that form of the government in which the main acting subject is the head of state is considered. The proceeding from it, the establishment of intrinsic signs of specified views of the republic is expedient. It is about formal and certain signs, the existence of separate constitutional precepts of the law, the accounting of political and legal reality. The answer is hidden in the concept of the form of the government, and indirectly through it - in the effect of the authorities, its influence on the relations formed in the state. To understand the positions opening this process theoretical constitutional and legal research is conducted. The positions of various authors on the matter are considered, historical material is generalized and conclusions are located. Following the norms of constitutional law, it is necessary to emphasize that on formal legal grounds the form of the government of modern Russia is presidential republic in spite of the fact that at it there is a number of signs peculiar to the superpresidential republic. The amendments being suggested to be made in the Constitution will allow deciding this item finally.

Keywords: republic, presidential republic, comparative and legal analysis, forms of government, succession of authorities, elections.

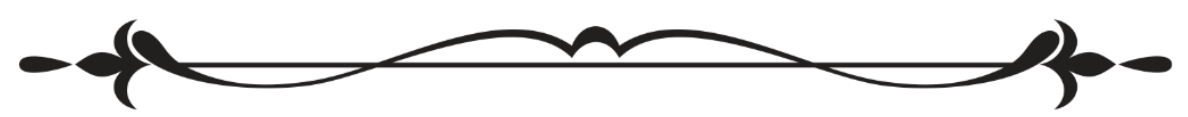

В соответствии с ч. 1 ст. 1 Конституции Российской Федерации форма правления современной России - республика [1]. Форма правления как научная категория соответствует предмету изучения теории государства и права. Однако конституционное право вносит большую степень ясности по специфике рассматриваемого вопроса. При этом следу- 


\section{Социально-экономический и әуманитарный журнал Красноярского ГАУ. 2020. №1}

ет обратить внимание на то, что некоторые авторы в своих исследованиях либо не конкретизируют вид республики (С.А. Авакьян, М.Б. Смоленский), либо комплексно не раскрывают вопрос принадлежности РФ к тому или иному виду республики (М.В. Баглай). Однако данное обстоятельство не отменяет факта возможной детализации точек зрения по данному вопросу $[4 ; 5 ; 18]$.

В настоящее время в науке конституционного права единая позиция относительно формы правления, сформировавшейся в РФ, отсутствует. В этой части, справедливо отмечает М.Н. Марченко, «множественность форм государства является абстракцией и порождением теории, в то время как на практике встречаются самые разнообразные комбинации признаков того или иного вида монархии или республики, что является объективным, поскольку историческое развитие любого государства различно по отношению к остальным государствам» [11].

Сложившаяся практика позволяет выделить следующие виды республики: парламентскую, президентскую, смешанную, суперпрезидентскую и множество других. При этом в рамках отдельного вида республики могут существовать подвиды (например, Россия сегодня, по мнению ряда авторов, представляет собой «президентскую республику с сильной исполнительной властью») [13, с. 72]. Имеют место и другие мнения. Так, ряд ученых-правоведов полагают, что по форме правления современная Россия, во-первых, смешанная республика (О.Е. Кутафин, В.И. Фадеев); во-вторых, президентская (М.Н. Марченко, В.С. Нерсесянц, Л.А. Морозова, В.Е. Чиркин); в-третьих, суперпрезидентская (А.В. Малько, А.А. Кондрашов) $[8 ; 9 ; 11-14 ; 19 ; 20]$.

Исходя из этого, целесообразным является установление сущностных признаков указанных видов республики. Речь идет о формальноопределенных признаках, наличии отдельных конституционноправовых норм, учете политико-правовой действительности. Следует полагать, что ответ скрыт в понятии формы правления и опосредованно через нее - в сущности власти, ее влиянии на отношения, формирующиеся в государстве. Целесообразно выделить следующие признаки формы правления: во-первъц, это способ образования и организации государственной власти $[14$, с. 245$]$; во-вторьх, характеристика вопросов организации верховной государственной власти, порядок образования ее органов и их взаимоотношения между собой и с населением [12, с. 36]; в-третьих, вопросы взаимоотношения органов государственного управления с населением, которое может выражаться в реализации гражданами своих прав, свобод и законных интересов [16, с. 330], ином реальном влиянии граждан на принимаемые государством решения [17, c. 93]; в-четвертых, отражение позиций правящей силы, присутствующей в государстве [13, с. 67].

Примечательно, что исследователи выводят приемы и способы осуществления государственной власти за пределы формы правления, 
делегируя данный признак политико-правовому (государственному) режиму [14, с. 245]. Однако мы должны учитывать, что форма правления имеет не только формальный аспект своего содержания, но и реальный. Поэтому следует полагать, что способ ее осуществления целесообразно также включать в понятие формы правления, так как он имеет прямое к ней отношение, поскольку его реализация прослеживается через призму принципа разделения властей - систему сдержек и противовесов. Так, например, ряд исследователей не акцентируют внимание на полномочиях Президента РФ в части его определяющей роли при назначении федеральных судей, судей Верховного суда и Конституционного суда на соответствующие посты, что свидетельствует практически о значимом контроле Президента РФ в данном случае над судебной ветвью власти. В свою очередь, назначение министров федерального правительства также прерогатива Президента РФ и также свидетельствует о его влиянии на исполнительную ветвь власти. С принятием поправок в Конституцию РФ ситуация изменится незначительно.

Сравнительно-правовой анализ подтверждает, что установление отдельных признаков республики корреспондируется, т. е. часть из них может иметь и конституционная монархия. Например, по выборности представителей органов государственной власти системы избирательного права в ФРГ (парламентская республика) и Великобритании (конституционная монархия) примерно схожи [12, с. 37]. При этом решающее значение имеет реальность, а не формальность выборов. Таким образом, не исключены случаи, если в республике выборы высших органов государственной власти проходят формально, это говорит о реальной политико-правовой ситуации в государстве.

Вопрос об ответственности верховной власти перед народом и (или) законом. Исходя из Преамбулы и ч. 2 ст. 80 Конституции РФ, Президент Российской Федерации является гарантом Конституции Российской Федерации. Несмотря на установленную Конституцией неприкосновенность Президента РФ, согласно ст. 91, уже в ст. 93 предусмотрен порядок его отрешения от должности. Этот признак свойственен только президентской республике. Фактически речь идет о юридической ответственности главы государства. В то же время аналогичные нормы в ряде монархических стран отсутствуют (Великобритания, Испания, Япония и иные). Например, из Акта о престолонаследии (1701) вытекает, что король (королева) Великобритании не несет ответственности ни перед народом, ни перед законом, ибо в ответе перед ними - Правительство, в том числе и уголовной, что также исходит из положения о том, что монарх стоит над законом (согласно английской традиции) [10, с. 189].

Реализация принципа коллегиальности, свойственного для республики, имеет смысл лишь в том случае, если в государстве существует баланс каждой из ветвей власти, реализуется система сдержек и противовесов. Несмотря на то, что в Великобритании и иных европейских мо- 


\section{Социально-экономический и әуманитарный журнал Красноярского ГАУ. 2020. №1}

нархиях верховная власть принадлежит монарху, у монарха ряд полномочий относятся к спящим (акты правотворчества Великобритании предусматривают широкий перечень полномочий монарха, которыми он не пользуется). Следует подчеркнуть, что данным признаком с отдельными оговорками обладает как республика, так и парламентарная монархия.

Вопрос о сменяемости власти. Под сменяемостью власти следует понимать сменяемость главы государства и иных избираемых должностных лиц. Ряд конституций государств прямо предусматривает право пожизненного исполнения полномочий президента (правление Ким Чен Ир в Северной Корее), в таких случаях налицо особая связь формы правления и формы государственного режима [17, с. 103]. Одновременно имеют место и выборные монархии (например, Объединенные Арабские Эмираты, где главой государства избирается на пятилетний срок один из наследственных эмиров). В этом случае вести речь о сменяемости власти, наличии демократического режима в государстве говорить не приходится [17, с. 97]. Необходимо отметить, что признак сменяемости органов государственной власти, в частности высших, не тождественен признаку срочности (ограничение срока полномочий власти) [12, с. 37; 17, с. 97]. Срочность применительно к форме правления - республике можно использовать лишь только к лидеру государства (президенту, премьер-министру, канцлеру и иным) за исключением случаев формальной или фактической передачи высшей власти в государстве по наследству. Определить универсальные критерии сменяемости власти затруднительно, поскольку в каждом конкретном случае она имеет свое содержание. Требует пояснения вопрос включения в признак сменяемости фактора внешнего воздействия. Объективно реализация сменяемости власти в этом случае будет иметь место, только если о ней говорить в геополитическом плане.

По мнению А.Ф. Кистяковского, государственная власть в правовом смысле понимается как отношение одной воли и другой, господство одной воли над другой. К данному определению следует добавить следующее уточнение: государственная воля имеет свои проявления, выражающиеся как в установленном формально-правовом положении государства и населения, так и в реальных действиях, последствиях и причинной связи между ними, резюмирующих фактическое правовое положение данных субъектов, сложившееся в государстве [7, с. 298].

Таким образом, сущностными признаками республики являются: 1) фактическая и (или) формальная выборность органа высшей государственной власти гражданами или органами государственной власти, действующими от лица граждан, за исключением выборных монархий, республик с пожизненным президентством (или иным лидерством) в форме наследования; 2) ограничение срока полномочий органа высшей государственной власти - лидера государства (президент, премьерминистр, канцлер и т. д.) в случае республик с демократическим или ав- 
торитарным режимом; действительное или возможное отсутствие подобных ограничений (в случае передачи высшей власти в государстве по наследству, а также иного вида правопреемства); 3) зависимость факта образования высшего органа государственной власти от избирателей, которая носит формальный и (или) реальный характер (факт реализации отсутствует в случае выборной монархии); 4) наличие фактической и (или) формальной ответственности верховной власти перед народом и (или) законом.

В свою очередь, Л.А. Морозова детализирует признак: «о праве президента назначать референдумы по наиболее важным общественнополитическим вопросам и право введения чрезвычайного положения, право законодательной инициативы и право утверждения законов путем их подписания, право издания нормативных актов и право объявления войны и заключения мира и многие, многие другие» [16, с. 333].

B.Е. Чиркин указывает на личный авторитет главы государства как признак республики, не носящий формально-правового характера, тем не менее, в сочетании с «реальным положением дел» способствующий пониманию РФ как президентской республики. Полностью согласиться с утверждением ученого нельзя, поскольку помимо тех формальноправовых признаков, которые свойственны смешанной республике, в Конституции РФ нашли свое отражение и те, которые свойственны президентской республике, о чем будет сказано позже [20, с. 16-17].

М.Н. Марченко констатирует, что «в России президентская республика характеризуется наличием чрезвычайно сильной власти главы государства - президента. Поэтому форму правления современной России зачастую именуют суперпрезидентской республикой» [11, с. 260]. Л.П. Рассказов среди признаков рассматриваемой республики выделяет несменяемость главы государства $[17$, с. 103]. Л.А. Морозова обозначает РФ как президентскую республику с сильной исполнительной властью $[13$, c. 72]. Следует полагать, что автор ведет речь о суперпрезидентской республике, такой вывод целесообразен хотя бы потому, что суперпрезидентская республика позиционируется как разновидность президентской республики (родовой признак), ведь данный вывод вытекает из работ отдельных ученых.

Среди признаков видится несменяемость лидера государства: «это подтверждается, во-первых, увеличением срока президентских полномочий с четырех до шести лет; во-вторых, часть глав регионов не избираются непосредственно населением путем прямых выборов, а назначаются парламентами субъектов Федерации по представлению Президента РФ; в-третьих, он же назначает всех руководителей в системе МВД РФ, а также в системе регионов» [13, с. 72].

Оценочность суждений применительно к суперпрезидентской республике имела место и ранее. Так, А.Г. Орлов определял суперпрезидентскую республику как систему «государственного управления, основ- 


\section{Социально-экономический и әуманитарный журнал Красноярского ГАУ. 2020. №1}

ной чертой которой является гипертрофированная, неконтролируемая президентская власть» [15, с. 112].

Думается, что истина состоит в утверждении Н.А. Бобровой: «Из президентской формы правления российская модель впитала в себя лишь то, что усиливает Президента, а из парламентской - лишь то, что ослабляет парламент, например возможность его роспуска Президентом, что исключено в президентской республике» [6, с. 36].

На основании обозначенных признаков смешанной, президентской и суперпрезидентской республики целесообразно выяснить их соотношение в части формально-правового и политико-правового отражения. Признаки смешанной республики соответствуют закрепленным конституционно-правовым положениям: 1) президент в формальноправовом смысле отделен от руководства исполнительной властью, которая возлагается на председателя правительства (ст. 110: «Исполнительную власть Российской Федерации осуществляет Правительство Российской Федерации. Правительство Российской Федерации состоит из Председателя Правительства Российской Федерации, заместителей Председателя Правительства Российской Федерации и федеральных министров»); 2) глава государства имеет право роспуска парламента или его нижней палаты (ч. 4 ст. 111: «После трехкратного отклонения представленных кандидатур Председателя Правительства Российской Федерации Государственной Думой Президент Российской Федерации назначает Председателя Правительства Российской Федерации, распускает Государственную Думу и назначает новые выборы»; ч. 4 ст. 117 КРФ: «Председатель Правительства Российской Федерации может поставить перед Государственной Думой вопрос о доверии Правительству Российской Федерации. Если Государственная Дума в доверии отказывает, Президент в течение семи дней принимает решение об отставке Правительства Российской Федерации или о роспуске Государственной Думы и назначении новых выборов»); 3) парламент вправе выражать недоверие (порицание) правительству, но вопрос об отставке решается президентом (ч. 3 ст. 117: «Государственная Дума может выразить недоверие Правительству Российской Федерации»); 4) президент и парламент избирается сроком на шесть лет гражданами Российской Федерации на основе всеобщего равного и прямого избирательного права при тайном голосовании»; ст. 1 Федерального закона от 22.02.2014 № 20-ФЗ «О выборах депутатов Государственной Думы Федерального Собрания Российской Федерации»: «Депутаты Государственной Думы Федерального Собрания Российской Федерации ... избираются гражданами Российской Федерации на основе всеобщего равного и прямого избирательного права при тайном голосовании») [2]; 5) парламент может начать процедуру отрешения президента от должности (ст. 93); 6) глава государства, как правило, председательствует на заседаниях Совета министров и утверждает его решения (п. «б» ст. 83); 7) парламент участвует в процессе формирования правительства (п. «а» ст. 83) [1]. 
Справедливости ради, следует заметить, что последние четыре признака свойственны также и президентской республике. В свою очередь, признаки президентской республики соответствуют следующим конституционно-правовым положениям: 1) в руках президента сосредоточены полномочия главы государства и главы правительства, при этом не обязательно, чтобы президент являлся главой Правительства в формально-правовом смысле (п. «д» ст. 83: «...назначает на должность и освобождает от должности заместителей Председателя Правительства Российской Федерации, федеральных министров»; А.А. Кондрашов пишет: «Существует некий формальный дуализм и в управлении министерствами, когда «силовые» ведомства (МВД, ФСБ, Минобороны, Минюст и др.) напрямую подчиняются Президенту и не подконтрольны председателю Правительства. В настоящее время Президент РФ непосредственно руководит деятельностью отдельных федеральных органов исполнительной власти, общее число которых составляет более 20 \% от их общего числа. За Правительством остается незначительная координация деятельности органов управления, подчиненных непосредственно Президенту РФ») [9, с. 40]; 2) Президент самостоятельно формирует правительство, которое подотчетно ему, а не парламенту, за исключением ответственности по отдельным государственным вопросам, в частности бюджету (так, исходя из п. «а» ст. 83 и ч. 4 ст. 111, фактически президент формирует правительство, а по ч. 1 и 2 ст. 117, распускает его); 3) президент имеет право вето в отношении принимаемых парламентом нормативно-правовых актов, которое может быть преодолено при повторном рассмотрении таких актов (ч. 3 ст. 107: «Если Президент Российской Федерации в течение четырнадцати дней с момента поступления федерального закона отклонит его, то Государственная Дума и Совет Федерации в установленном Конституцией Российской Федерации порядке вновь рассматривают данный закон. Если при повторном рассмотрении федеральный закон будет одобрен в ранее принятой редакции большинством не менее двух третей голосов от общего числа членов Совета Федерации и депутатов Государственной Думы, он подлежит подписанию Президентом Российской Федерации в течение семи дней и обнародованию»); 4) президент правомочен отправить кабинет министров персонально или всем кабинетом в отставку (ч. 1 и 2 ст. 117), однако в нашем случае в отставку правительство отправляется лишь в полном составе; 5) в руках президента сосредоточена огромная политическая, военная и социально-экономическая власть, что можно проследить через анализ ст. 88, ч. 1 ст. 104, п. «д» ст. 84, ч. 2 ст. 87; 6) глава государства утверждает бюджет страны, оставляя функции контроля по его принятию за парламентом (ч. 5 ст. 101, п. «а» ст. 106, п. «а» ч. 1 ст. 114).

Рассматривая в совокупности как формальное, так и фактическое правовое положение Президента РФ, следует подчеркнуть, что форма правления, установленная в России, соответствует президентской республике. 


\section{Социально-экономический и әуманитарный журнал Красноярского ГАУ. 2020. №1}

Что касается признаков, свойственных суперпрезидентской республике: вопросы несменяемости власти, превалирование одной правящей партии, - они имеют место в той или иной стране.

Примечательно, что еще в 2004 г. А.В. Малько писал о РФ, как о суперпрезидентской республике [12, с. 67], указывая на то, что необходимо придерживаться мировых стандартов конституционных ограничений, характерных именно для президентских республик, а не пытаться их обходить в угоду конъюнктурным соображениям. В частности, «единоличное» право президента без согласия парламента назначать ключевых министров и даже практически произвольно распускать Государственную думу РФ выходит за рамки действующих президентских республик. Подобный «передел» власти в пользу президента и исполнительных структур не уравновешивает их с законодательной и судебной властями, нарушает систему взаимных сдержек и противовесов, что оставляет в принципе соблазн при удобном случае в целях восстановления справедливости перераспределить эту власть, в том числе и в произвольном порядке. Поэтому в современной России принцип разделения властей воплощается в жизни специфическим образом.

Следуя нормам конституционного права, необходимо подчеркнуть, что по формально-правовым основаниям формой правления современной России является президентская республика, несмотря на то, что в ней присутствует ряд признаков, свойственных суперпрезидентской республике. Полагаем, что вносимые в Конституцию изменения позволят окончательно определиться с этим вопросом.

\section{Литература}

1. Конституция Российской Федерации (принята всенародным голосованием 12.12.1993) (с учетом поправок, внесенных Законами РФ о поправках к Конституции РФ от 30.12.2008 № 6-ФКЗ, от 30.12.2008 № 7-ФКЗ, от 05.02.2014 № 2-ФКЗ, от 21.07.2014 № 11-ФКЗ) // Консультант плюс: Законодательство (дата обращения: 27.12.2019).

2. О выборах депутатов Государственной Думы Федерального Собрания Российской Федерации: федер. закон от 22.02.2014 № 20-Ф3 (ред. от 29.05.2019) // Консультант плюс: Законодательство. URL: www.consultant.ru (дата обращения: 27.12.2019).

3. Об изменении срока полномочий Президента Российской Федерации и Государственной Думы: закон РФ о поправке к Конституции РФ от 30.12.2008 № 6-ФК3 // Консультант плюс: Законодательство. URL: www.consultant.ru (дата обращения: 27.12.2019).

4. Авакъян C.A. Конституционное право России. Учебный курс: учеб. пособие: в 2 т. 5-е изд., перераб. и доп. М.: Норма : ИНФРА-М, 2014. Т. 1. 864 c.

5. Баглай M.B. Конституционное право Российской Федерации: учеб. для вузов. 6-е изд., изм. и доп. М.: Норма, 2007. 784 с. 
6. Боброва Н.А. 20 лет и 20 недостатков Конституции России // Конституционное и муниципальное право. 2013. № 3. С. 33-37.

7. Кистяковский А.Ф. Лекции по общему государственному праву: учеб. пособие. М., 1912.

8. Козлова, Е.И., Кутафин О.Е. Конституционное право России: учебник / Москов. гос. юрид. ун-т им. О.Е. Кутафина. 5-е изд., перераб. и доп. М.: Проспект, 2015. 578 с.

9. Кондрашев A.A. Суперпрезидентская республика в России: миф или реальность? // Вестник Университета имени О.Е. Кутафина. 2018. №6 (46). C. $34-42$.

10. Конституционное право государств Европы: учеб. пособие для студентов вузов / отв. ред. Д.А. Ковачев; Ин-т законодательства и сравнит. правоведения при Правительстве Рос. Федерации. М.: Волтерс Клувер, 2005. 309 с.

11. Марченко М.Н. Теория государства и права: учебник. 2-е изд., перераб. и доп. М.: Велби; Проспект, 2004. 640 с.

12. Матузов Н.И. Теория государства и права: курс лекций / под ред. Н.И. Матузова, А.В. Малько. 3-е изд., перераб. и доп. М.: Норма; Инфра-М, 2012. 640 с.

13. Морозова Л.А. Теория государства и права: учебник. 5-е изд., перераб. и доп. М.: Норма; ИНФРА-М, 2015. 464 с.

14. Нерсесянц B.C. Общая теория права и государства: учебник. М.: Норма; ИНФРА-М, 2012. $560 \mathrm{c.}$

15. Орлов А.Г., Крутоголов М.А., Крылова Н.С. и др. «Суперпрезидентская» республика латиноамериканского типа // Современное буржуазное государственное право. Критические очерки. Основные институты. № 2 / отв. ред. В.А. Туманов. М.: Наука, 1987. 368 с.

16. Радько Т.Н., Лазарев В.В., Морозова Л.А. Теория государства и права: учебник / Моск. гос. юрид. ун-т им. О.Е. Кутафина. М.: Проспект, 2014. $564 \mathrm{c}$.

17. Рассказов Л.П. Теория государства и права: углубленный курс: учебник. М.: РИОР; ИНФРА-М, 2015. 559 с.

18. Смоленский М.Б., Мархгейм М.В. Конституционное право Российской Федерации: учебник. Ростов н/Д: Феникс, 2007. 445 с.

19. Фадеев В.И. Конституционное право: учебник. М.: Проспект, 2014. 584 с. 20. Чиркин B.E. Постсоциалистическое государство XXI века // Журнал российского права. 2008. № 5. С. 3-17.

\section{Literatura}

1. Konstitucija Rossijskoj Federacii (prinjata vsenarodnym golo-sovaniem 12.12.1993) (s uchetom popravok, vnesennyh Zakonami RF o popravkah $\mathrm{k}$ Konstitucii RF ot 30.12.2008 № 6-FKZ, ot 30.12.2008 № 7-FKZ, ot 05.02.2014 № 2-FKZ, ot 21.07.2014 № 11-FKZ) // Konsul'tant pljus: Zakonodatel'stvo (data obrashhenija: 27.12.2019). 


\section{Социально-экономический и әуманитарный журнал Красноярского ГАУ. 2020. №1}

2. O vyborah deputatov Gosudarstvennoj Dumy Federal'nogo Sobra-niya Rossijskoj Federacii: feder. zakon ot 22.02.2014 № 20-FZ (red. ot 29.05.2019) // Konsul'tant plyus: Zakonodatel'stvo. URL: www.consultant.ru (data obrashcheniya: 27.12.2019).

3. Ob izmenenii sroka polnomochij Prezidenta Rossijskoj Federa-cii i Gosudarstvennoj Dumy: zakon RF o popravke k Konstitucii RF ot 30.12.2008 № 6-FKZ // Konsul'tant plyus: Zakonodatel'stvo. URL: www.consultant.ru (data obrashcheniya: 27.12.2019).

4. Avak'jan S.A. Konstitucionnoe pravo Rossii. Uchebnyj kurs: ucheb. posobie: v 2 t. 5-e izd., pererab. i dop. M.: Norma : INFRA-M, 2014. T. 1. 864 s.

5. Baglaj M.V. Konstitucionnoe pravo Rossijskoj Federacii: ucheb. dlja vuzov. 6-e izd., izm. i dop. M.: Norma, 2007. $784 \mathrm{~s}$.

6. Bobrova N.A. 20 let i 20 nedostatkov Konstitucii Rossii // Konstitucionnoe i municipal'noe pravo. 2013. № 3. S. 33-37.

7. Kistjakovskij A.F. Lekcii po obshhemu gosudarstvennomu pravu: ucheb. posobie. M., 1912.

8. Kozlova, E.I., Kutafin O.E. Konstitucionnoe pravo Rossii: ucheb-nik / Moskov. gos. yurid. un-t im. O.E. Kutafina. 5-e izd., pererab. i dop. M.: Prospekt, 2015. $578 \mathrm{~s}$

9. Kondrashev A.A. Superprezidentskaja respublika v Rossii: mif ili real'nost'? // Vestnik Universiteta imeni O.E. Kutafina. 2018. №6 (46). S. $34-42$.

10. Konstitucionnoe pravo gosudarstv Evropy: ucheb. posobie dlja studentov vuzov / otv. red. D.A. Kovachev; In-t zakonodatel'stva i sravnit. pravovedenija pri Pravitel'stve Ros. Federacii. M.: Volters Kluver, 2005. $309 \mathrm{~s}$.

11. Marchenko M.N. Teorija gosudarstva i prava: uchebnik. 2-e izd., pererab. i dop. M.: Velbi; Prospekt, 2004. 640 s.

12. Matuzov N.I. Teorija gosudarstva i prava: kurs lekcij / pod red. N.I. Matuzova, A.V. Mal'ko. 3-e izd., pererab. i dop. M.: Norma; Infra-M, 2012. $640 \mathrm{~s}$.

13. Morozova L.A. Teorija gosudarstva i prava: uchebnik. 5-e izd., pererab. i dop. M.: Norma; INFRA-M, 2015. 464 s.

14. Nersesjanc V.S. Obshhaja teorija prava i gosudarstva: uchebnik. M.: Norma; INFRA-M, 2012. $560 \mathrm{~s}$.

15. Orlov A.G., Krutogolov M.A., Krylova N.S. i dr. «Superprezidentskaja» respublika latinoamerikanskogo tipa // Sovremennoe burzhuaznoe gosudarstvennoe pravo. Kriticheskie ocherki. Osnovnye instituty. № 2 / otv. red. V.A. Tumanov. M.: Nauka, 1987. $368 \mathrm{c}$.

16. Rad'ko T.N., Lazarev V.V., Morozova L.A. Teorija gosudarstva i prava: uchebnik / Mosk. gos. jurid. un-t im. O.E. Kutafina. M.: Prospekt, 2014. $564 \mathrm{~s}$. 
17. Rasskazov L.P. Teorija gosudarstva i prava: uglublennyj kurs: uchebnik. M.: RIOR; INFRA-M, 2015. $559 \mathrm{s.}$

18. Smolenskij M.B., Marhgejm M.V. Konstitucionnoe pravo Rossijskoj Federacii: uchebnik. Rostov n/D: Feniks, 2007. 445 s.

19. Fadeev V.I. Konstitucionnoe pravo: uchebnik. M.: Prospekt, 2014. 584 S.

20.Chirkin V.E. Postsocialisticheskoe gosudarstvo XXI veka // Zhurnal rossijskogo prava. 2008. № 5. S. 3-17.

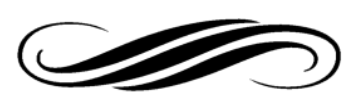

